University of Nebraska - Lincoln

DigitalCommons@University of Nebraska - Lincoln

November 2003

\title{
Incidence and correlates of breast milk feeding in hospitalized preterm infants
}

\author{
K. A. Espy \\ University of Nebraska-Lincoln, kespy2@unl.edu \\ T. E. Senn
}

Follow this and additional works at: https://digitalcommons.unl.edu/dcnlfacpub

Part of the Neurosciences Commons

Espy, K. A. and Senn, T. E., "Incidence and correlates of breast milk feeding in hospitalized preterm infants" (2003). Developmental Cognitive Neuroscience Laboratory - Faculty and Staff Publications. 12. https://digitalcommons.unl.edu/dcnlfacpub/12

This Article is brought to you for free and open access by the Developmental Cognitive Neuroscience Laboratory at DigitalCommons@University of Nebraska - Lincoln. It has been accepted for inclusion in Developmental Cognitive Neuroscience Laboratory - Faculty and Staff Publications by an authorized administrator of DigitalCommons@University of Nebraska - Lincoln. 


\title{
Incidence and correlates of breast milk feeding in hospitalized preterm infants
}

\author{
Kimberly Andrews Espy*, Theresa E. Senn \\ Department of Family \& Community Medicine, School of Medicime, Southern Illinois Unitersity, Carbondule, IL 629016503, USA
}

\begin{abstract}
The majority of cpidemiological studies of breast feeding have been conducted in healthy, fullterm infant samples. Little is known about the incidence and correlates of breast milk feeding in preterm infants, particularly in those born outside of metropolitan areas. Thercfore, hospital medical charts of 151 consecutively admitted preterm infants ( $\leqslant 34$ weeks gestational agc), in the US, were revicwed and daily feeding, maternal demographic, pregnancy, and infant medical condition information was recorded, About half of the preterm infant sample was fed breast milk, receiving at least one breast milk feeding per day for $44 \%$ of their hospital stay. Although maternal demographic variables were important predictors of breast milk feeding, perinatal medical condition of the infant playcd a unique role in feeding practices in preterm infants. Specific interventions could be targeted to families with preterm infants to modestly incrcase population breast feeding rates.
\end{abstract}

(6) 2003 Elsevier Ltd. All rights reserved.

Keywords: Preterm infant; Bręust feeding: Incidence; USA

\section{Introduction}

Despite evidence that breastfed fullterm infants sufler from fewer infections (Cushing ct al., 1998; Paradise \& Rockette, 1997; Wright, Bauer, Naylor, Sutcliffe, \& Clark, 1998), only about $60 \%$ of infants in the United States are ever breastfed (Ryan, 1997). Recently, mothers of preterm infants have been cncouraged to feed their infants breast milk, including an official policy statement by the Amcrican Academy of Pediatrics (1997) that recognizes the benefit of human milk for preterm infants. Mothers of preterm infants, however, ate more likely to be economically disadvantaged, unmarried, less educated, and to smoke during pregnancy when compared to mothers of fulltem infants (Chomitz, Cheung, \& Licberman, 1995). In comparison to fullerm infants, preterm infants are at greater medical risk and require prolonged hospitalization, both of which may affect the likelihood of breast milk feeding

\footnotetext{
"Corresponding author. Tel.: + 1-618-453-3207; fax: +1. 618-453-1859.

E-mail address: kespy@siumed.edu (K.A. Espy).
}

in this population. Both maternal and infant factors may play unique roles in determining the incidence and correlates of breast milk fecding in preterm infants. Estimates of brcast feeding initiation rates in those born preterm and of low birth weight $(<2500 \mathrm{~g})$ vary considerably, ranging from $48 \%$ (Furman, Minich, \& Hack, 1998; Ryan, 1997) to $73 \%$ (Fuman, Minich, \& Hack, 2002) in the US. These breast fecding initiation rates for preterm and low birth weight infants are lower than rates for full term infants (Lefebvre \& Ducharme. 1989; Ryan, 1997; Starbird, 1991). Although breast feeding initiation rates have increased in recent years, particularly among subgroups of women who historically are less likely to breastfeed, such as mothers of low birth weight infants (Ryan, 1997), rates remain well below the goals of Healthy People 2010 (Department of Health and Human Services, 2000).

The percentage of mothers who choose to feed their infants breastmilk differs systematically among subgroups of women, with those who are older, married, more educated (DaVanzo, Starbird, \& Leibowitz, 1990; Grossman, Fitzsimmons; - Larsen-Alexander, Sachs; Harter, 1990; Ryan, Wysong. Martinez, \& Simon, 1990), 
Caucasian, or more advantaged economically more likely to breast feed than those who are not (Grossman et al., 1990; Kennedy \& Visness, 1997; Ryan, 1997; Ryan et al., 1990). Women who smoke during pregnancy, on the other hand, are less likely to breast fced (Grossman et al., 1990), and are more likely to terminate breast feeding early (Hill \& Aldag, 1996). Interestingly, parity (c.g., Kuan et al., 1999; Littman, Medendorp, \& Goldfarb, 1994) and maternal employment (c.g., I.indberg. 1996; Lizarraga, Mathr, Wingard, \& Felice. 1992) have becn related inconsistently to brcast feeding.

The demographic correlates of brcast focding preterm or low birth weight infants tarely have been investigated. In the US, matemal demographic correlates of breast milk feeding very low birth weight (wcighing $<1500 \mathrm{~g}$ at birth) infants were similar to those of brcast feeding fullterm infants; that is, mothers who wcre older, marricd, and Caucasian were morc likely to initiate pumping (Furman et al., 1998). Older, married, morc highly educated, Caucasian mothers also were more likely to continue to provide their very low birth weight infants with breastmilk beyond 40 wccks corrected age, compared to mothers who initiated but discontinued brcastmilk feepding beforc 40 weeks (Furman et al, 2002). In contrast, in studics conducted with low birth wcight infants outside of the US, there was no relation between breast feeding and matcrnal age ( $\mathrm{Yu}$, Jamicson, \& Bajuk, 1981) or maternal cducation (Boo \& Goh, 1999).

Interestingly, infant medical risk variables, such as birth weight and gestational age, are unrclated to breast feeding in unselected samples of healthy, largely torm infants (DaVanzo ct al., 1990; Kuan et al., 1999; Ryan et al. 1990). In unselected samples, however, few infants with birth weights below $2500 \mathrm{~g}$ are included (Grossman et al., 1990; Lizarraga ot al., 1992). Because the incidence of medical complications in infants who weigh over $2500 \mathrm{~g}$ at birth is quite low, the ability 10 delect the influences of perinatal stalus on breast feeding in this group is limited with such designs.

In preterm and low birth weight infants, where there is large variability in modical risk, infant health and breast feeding may be related more strongly. In Australian preterm infants, those born at later gestational ages were more likely to be breastfed than those born at carlicr gestational ages (Yip, Lee, \& Shechy, 1996). Similarly, very low birth weight infants in Malaysia were more likely to be breastfed if thcy weighed more at birth, began enteral focdings at an earlier age, and werc ventilated for fewer days (Boo \& Goh, 1999). In contrast, very low birth weight infants in a large, metropolitan, US hospital werc more likely to be breast fed if they were born at earlicr gestational ages and weighed less at birth (Furman et al., 2002), Others found no association betwecn birth weight or gestational agc and breast feeding in very low birth weight infants in the US (Furman et al., 1998) and Australia (Yu et al., 1981).

In preterm infants in particular, the correlates of breast milk feeding initiation may differ from the continuation, or duration, of breast milk feeding, as the barriers to maintaining breast milk feeding a hospitalized, sick infant, differ from that of hcalthy fullterm pecrs in the home environment, such as the need to express and store breast milk and transport it to the hospital, and the neurophysiological immaturity of the infant that often precludes nursing directly from the breast. Among mothers who chose to breast milk fced their very low birth weight infants, fewer apnea episodes, fewer hospital days, and fewer days of oxygen therapy were associated with continued brcastmilk provision at hospital discharge (Furman et al., 1998). However, infant halth variables werc unrelated to breast milk feeding at 40 wccks corrected age (Furman et al. 2002), approximately 2 weeks after sample mean discharge date.

Therc remains a paucity of studies examining brcast milk feeding in preterm infants, without a clear consensus of the correlates of breast milk feeding. By identifying the correlates of leeding, intervention programs can be targeted to the needs of specific populations to increase the likelihood of success (Frcudenberg et al., 1995). Interestingly, higher medical risk was related to a greater incidence of breast milk feeding initiation and brcast milk feeding at hospital discharge in mother-infant pairs in a large, urban US hospital, where in those studies conducted outside the US, breast milk fecding was related to variables signifying lower medical risk. Even in the US, it is likely that brcast milk feeding rates for preterm infants differ considerably. Because of the regionalization of modern neonatal care to decrease mortality. NICUs serve patients who differ dramatically in demographic characteristics that may, in turn, affect breast milk fecding rates. Residents of rural, more economically disadvantaged areas are less likely to engage in health promoting behaviors (c.g., exercise) and are more likely to engage in behaviors that are deictcrious to pregnancy hcalth, such as smoking, poor diet, and late initiation of prenatal care (e.g., Alcxy, Nichols, Heverly, \& Garzon, 1997; Miller, Clarke. Albrecht, \& Farmer, 1996). Thereforc, the purpose of this study was to detcrmine the incidencc and correlates of brcast milk leeding pattcrns in preterm infants from non-metropolitan NICU. The rates of breast milk feeding preterm infants born to residents of such areas were postulated to be lower than that reported from urban US medical centers. Furthermore, both matcrnal and infant corrclates were postulated to be related to breast milk fecding patterns, with preterm infants at greater medical risk who required more prolonged or intensive treatment heing less likely to be breast milk fod.
Ho
fan
are
anui
IICl
$x c m$
equi
ougl appri rangx perso from belor. Bure. monl Prete and for : mecr were redui (Hac hosp relia who han In nfo: feed feed he rav sup repl: here tion verı

Pro l. ror tuc N:L: 
tal.,

rcasl

ower

milk

ibly.

care

liffer

$y$, in

ural,

ly to

and

are

poor

lexy,

trke,

ie of

lates

irom

milk

Ireas

from

srnal

d to

is at d or
Methods

Subjects

Hospital medical charts were reviewed of all preterm infants consecutively admitted to a Neonatal Intensive Care Unit (NICU) of a regional hospital in the US, from January 1, 1997 through December 31, 1998. The NICU, an Advanced Care Level II unit with an exemption to treat infants down to $750 \mathrm{~g}$ who do not require major surgery, has a catchment area that cxtends roughly to the southern 21 counties of 1tlinois (radius of approximately 100 miles). In the catchment area, the range of the county population density was 20-101 persons/square milc, median household income was from $\$ 26,000$ to $\$ 33,000$, and the percentage of persons below poverty was from $13 \%$ to $30 \%$ (US Census Bureau, 2000). All preterm infants born during the 24month study period at $\leqslant 34$ wecks gestational age were included in this study ( $N=151$, range 25.0-34.5 weeks). Preterm infants with birth gestational ages $\geqslant 35$ weeks and fulterm infants with neonatal complications (e.g., for antibiotics due to maternal infection, presence of meconium in lungs, initial breathing difficulties) who were admitted to the NICU were excluded from participation in this study $(n=276)$ because of the reduced risk of medically related differences in outcome (Hack ct al., 1994) and because the typically brief hospital stay of thesc infants reduces the opportunity to reliably measure feeding practices. There were 2 infants who were excluded as outliers, one with an unconfirmed gestational age of 34 weeks with a birth weight of $3960 \mathrm{~g}$ and another whose number of days on oxygen was more than $7 \mathrm{SD}$ from the mean.

Infants were categorized by feeding groups based on information obtained from the charted hospital daily feeding records. During hospitalization, nursery staff recorded daily any fluid intake, including the time of feeding, amount ingested, and type of fluid. Because of the rural location of the NICU, many women had to travel long distances to the NICU to nurse or deliver expressed milk, which often resulted in some formula supplementation for infants. An unambiguous, casily replicable definition of breast milk feeding was chosen here. Breast milk feeding (BF) in preterm infants was defined as receiving any breast milk during hospitalization. Formula fed (FF) preterm infants were those who were fed formula cxclusively.

\section{Procedure}

Infant hospital medical record numbers were obtained from the NICU admission log. All charts were reviewed by 3 trained graduate students who were blind to the study hypotheses. All maternal and infant information was recorded from the preterm infant hospital medical charts becausc maternal medical records werc unavailable.

\section{Measures}

Maternal and infant variables available most com. monly across hospital infant medical charts were collected for analysis. Sample descriptor and feeding information was recorded, in addition to pertinent maternal and infant variables that have been demonstrated to be related to breast feeding previously. Matcrnal variables of interest werc: (1) Age at delivery ( $<21$ vs. $\geqslant 21$ ), (2) Race (Caucasian vs. minority). (3) Insurance status (privatc vs. Medicaid or none), (4) Prenatal smoking (present or absent), (\$) Parity (primiparous vs. multiparous), and (6) Marital status. Insurance status was used as a proxy for maternal socioeconomic status, as matcrnal income and education were not available in most hospital charts. lnfant variables were: (1) Birth weight, (2) Apgar score at 5 min ( $\leqslant 6$ vs, $\geqslant 7$ ), (3) Number of days hospitalized, and (4) Number of days on any oxygen. The high correlation of birth weight and gestational agc $(r=0.82)$ did not permit the use of both of these variables in the multivariate analyses. Birth weight, rather than gestational agc, was used as an infant characteristic because it is measured more precisely, is a more robust predictor of outcome, and it was hypothesized that parcnts would use infant weight, an obscrvable characteristic, when detcrmining feeding practices to a greater extent than relative maturity. Apgar score at $5 \mathrm{~min}$ was uscd as a summary measure of medical risk, as it was available on all charts and did not require prenatal records for quantification (e.g., Hobel, Hyvarinen, Okada, \& Oh, 1973).

\section{Design}

Pertinent percentages werc calculated to determine the pattern of breast milk feeding during hospitalization. Univariate ANOVA's were conducted to examinc feeding group differences on sample descriptor variables, as well as on the maternal and infant variables of interest. Follow-up comparisons among breast milk fed preterm infants were conducted, comparing those who were fed breast milk more consistently or less consistently during hospitalization $(\geqslant 45 \%$ vs. $<44 \%$ of hospital days; determined by median split). To investigate the correlates of breast milk feeding in preterm infants, two hierarchical logistic regression analyses were conducted. The first model included the maternal variables only, entered as a block. In the second model, infant variables were entered as a second block, to determine the contribution of preterm infant medical condition to breast milk feeding beyond that of maternal characteristics. Finally, follow-up percentages were 
calculated and univariate ANOVA's comparing those who were fed breast milk within 2 days of milk feeding initiation and within 2 days of hospital discharge were conducted to investigate feeding patterns across hospitalization. A 2-day window was used to allow for

Table 1

Sample characteristics

\begin{tabular}{|c|c|c|c|c|}
\hline \multirow[t]{2}{*}{ Variable } & \multicolumn{2}{|c|}{ Breast milk red } & \multicolumn{2}{|c|}{ Formula led } \\
\hline & $M / n$ & $\mathrm{SD} / \%$ & $M / n$ & $\mathrm{SD} / \%$ \\
\hline $\begin{array}{l}\text { Infunt geslational } \\
\text { age (weeks) }\end{array}$ & 31.8 & 2.2 & 31.6 & 2.5 \\
\hline \multicolumn{5}{|l|}{ Infant $\operatorname{sex}$} \\
\hline Males & 36 & & 40 & \\
\hline remules & 39 & & 35 & \\
\hline $\begin{array}{l}\text { Chronokgical age at } \\
\text { lst milk feeding } \\
\text { (days) }\end{array}$ & 3.2 & 2.5 & 3.0 & 2.0 \\
\hline $\begin{array}{l}\text { Conceptional age at } \\
\text { discharge (wccks) }\end{array}$ & 36.1 & 1.6 & 35.8 & 1.2 \\
\hline
\end{tabular}

Note: $p$-values for feeding group comparisons with pertinent $F$ or $\chi^{2}$ statistics were $>0.51$. variability in providing milk to the NICU for initial feeding and variability of timing of discharge on the last hospital day. För all inferential statistical analyses, a pvalue of 0.05 was used to establish significance.

\section{Results}

There werc 75 preterm infants $(49.7 \%$ ) who were fed any breast milk (BF) during hospitalization, and 76 pretcrm infants $(\$ 1.3 \%)$ who were fed exclusively formula (FF). BF preterm infants received breast milk for at least 1 feeding per day on an average duration of $43.6 \%$ of the days they were hospitalized. The number of days hospitalized ranged from 3 to $79(M=29.0 ;$ SD 18.9). On those days, the mean percentage of feedings at which they received brcast milk was $36.3 \%$. One quarter of BF preterms were fed breast milk on more than $66 \%$ of hospital days, whereas $27 \%$ were fed breast milk fot less than $25 \%$ of hospital days. In table 1 is the sample descriptor information. BF and FF groups were comparablc in gestational age, sex, age at first feeding. and conceptional age at hospital discharge.

Table 2

Maternal and infant variables by feeding group

\begin{tabular}{|c|c|c|c|c|c|c|}
\hline \multirow[t]{2}{*}{ Variable } & \multicolumn{2}{|c|}{ Breast milk feco } & \multicolumn{2}{|c|}{ Formula fed } & \multirow[t]{2}{*}{$F / \chi^{2}$} & \multirow[t]{2}{*}{$p$} \\
\hline & $M / n$ & $\mathrm{SD} / \%$ & $M / n$ & $\mathrm{SD} / \%$ & & \\
\hline Maternal age (yrs) & 26.2 & 6.0 & 23.1 & 5.5 & 10.78 & $<0.01^{\circ}$ \\
\hline Maternal race & & & & & 0.05 & $>0.82$ \\
\hline Caucasian & 63 & 84 & 64 & 85 & & \\
\hline Minority & 12 & 16 & 11 & 15 & & \\
\hline Marital státus & & & & & 0.34 & $>0.55$ \\
\hline Married & 38 & 60 & 37 & 55 & & \\
\hline Non-murried & 25 & 40 & 30 & 45 & & \\
\hline Prenatul smoking & & & & & 7.36 & $<0.01^{\circ}$ \\
\hline Yes & 19 & 28 & 33 & 52 & & \\
\hline No & 48 & 72 & 31 & 48 & & \\
\hline Insurance & & & & & 15.16 & $<0.0001^{\star \star}$ \\
\hline Privute & 36 & 58 & 16 & 24 & & \\
\hline Public/nonc & 26 & 42 & 50 & 76 & & \\
\hline Parity & & & & & 0.87 & $>0.35$ \\
\hline First & 44 & 68 & 51 & 75 & & \\
\hline Multipls & 21 & 32 & 17 & 25 & & \\
\hline Birth wcight $(\mathrm{kg})$ & 1.74 & 0.46 & 1.76 & 0.57 & 0.06 & $=0.80$ \\
\hline Hospital stay (duys) & 30.2 & 19.2 & 28.5 & 19.6 & 0.01 & $=0.91$ \\
\hline Oxygen (days) & 5.0 & 10.7 & 6.4 & 13.4 & 0.94 & $=0.33$ \\
\hline Apgar-5min & & & & & 5.24 & $c 0.03^{* \cdots}$ \\
\hline$\leqslant 6$ & 4 & 5 & 13 & 17 & & \\
\hline$\geqslant 7$ & 71 & 95 & 6.3 & 83 & & \\
\hline
\end{tabular}

Note: Not all subjects have complete data on all variables.

$p<0.05$.

$" p<0.01$.

$\cdots p<0.001$. 
initial

c last

. a $p^{+}$

te fed

id 76

sively

milk

ion of

Imber

0 ; SD

lys at

larter

$66 \%$

ik lor

.mple

were

sding.

Table 3

Relations among predictors and breast feeding status

\begin{tabular}{|c|c|c|c|c|c|}
\hline Construcl & $R^{2} \Delta$ & Adjusted odds ratio & $\mathrm{CI}$ & $x^{2}$ & $p$ \\
\hline Maternal variables & $16.6 \%$ & & & & $<0.03^{*}$ \\
\hline Age & & 3.70 & $1.2-11.5$ & 5.10 & $<0.03^{\circ}$ \\
\hline Race & & 1.05 & $0.3-3.7$ & 0.01 & $>0.93$ \\
\hline Marital status & & 1.50 & $0.5-4.8$ & 0.47 & $=0.49$ \\
\hline Insurance status & & 2.69 & $0.9-8.1$ & 3.06 & $<0.09$ \\
\hline Primiparous & & 0.68 & $0.2-2.1$ & 0.48 & 30.48 \\
\hline Smoking & & 0.51 & $0.2-1.4$ & 1.61 & $=0.20$ \\
\hline Infant variables & $10.3 \%$ & & & & $<0.05^{\circ}$ \\
\hline Birth weight & & 0.96 & $0.5-6.2$ & 0.0 & $>0.96$ \\
\hline Apgar score $-5 \mathrm{~min}$ & & 0.08 & $0,0-0.8$ & 4.79 & $<0.03^{*}$ \\
\hline Days of hospitalization & & 1.02 & $1.0-1.1$ & 0.57 & $>0.44$ \\
\hline Days on oxygen & & 0.94 & $0.9-1.0$ & 1.22 & $\therefore 0.26$ \\
\hline
\end{tabular}

Note: $N=83$ with completc data on all variables.

$p<0.05$.

In table 2 are the maternal and infant variables of interest as a function of feeding group. On average, mothers of BF infants were older at delivery, were more likely to have private insurance, and were less likely to smoke during pregnancy than $\mathrm{FF}$ infant mothers. Fceding groups did not differ in marital stalus, primiparity, or racc. BF infants were less likely to have an Apgar score of $\leqslant 6$ at 5 min than FF infants, but were comparable in birth weight, length of hospitalization, and days on oxygen, consistent with a similar hospital course between fceding groups.

Among BF infants, mothers of those who received breast milk morc consistently during hospitalization were older at delivery by an average of 3.18 years $(t[73]=2.32, p<0.03)$ than mother's of infants who received breast milk less consistently. There were no differences in the other maternal variables. Infants who received breast milk more consistently during hospitalization also were comparable in birth weight, days of hospitalization, and days on oxygen to those who received breast milk less consistently.

The results from the Iogistic regression models are depicted in Table 3. Both maternal demographics and infant medical condition, as blocks, accounted for significant variability in breast milk feeding odds. Among maternal predictors, women 21 years of age and older were 3.70 times more likely to use brcast milk to feed their preterm infant than younger women, whereas privately insured women were 2.69 times more likcly to use breast milk to fced their preterm infant than those with Medicaid or no health insurance $(p<0.09)$. Among infant medical condition variables, preterm infants at greater biologic risk (Apgar scores $\leqslant 6$ at $5 \mathrm{~min}$ ) were $92 \%$ less likely to be fed breast milk during hospitalization than were lower risk infants. Marital t status, maternal race, prenatal smoking, and parity were not associated significantly with breast milk feeding : odds, nor wcre birth wcight, days of hospitalization, or oxygen therapy.

There were 10 BF preterm infants (15.3\% of infants fed breast milk) who were fed brcast milk within 2 days of milk feeding initiation, too small to make maningful comparisons to those who did not receive breast milk in this time period. Within 2 days of hospital discharge, there were 55 BF preterm infants $(73.3 \%)$ fed breast milk. These BF infants were born later in gestation $\left(M_{\text {dill }}=2,8 \quad\right.$ weeks, $\left.F[1,73]=31.99, p=0.0001\right)$, weighed more at birth $\left(M_{\text {dif }}=0.6 \mathrm{~kg}, F[1,73]=34,77\right.$, $p<0,0001)$, were hospitalized for fewcr days $\left(M_{\text {diff }}=-23.5\right.$ days, $\left.F[1,73]=-34.31, p<0.0001\right)$, and received oxygen thcrapy for fewer days $\left(M_{\text {diff }}=-7.7\right.$ days, $\left.F[1,66)=7.47, p<0.01\right)$ than $B F$ preterm infants whose last breast milk fccding was more than 2 days prior to hospital discharge. Maternal demographic and pregnancy variables did not differ by breast milk fecding status within 2 days of hospital discharge.

\section{Discussion}

About half of preterm infants in this study were breast milk fed during hospitalization. These rates are lower than what is found at our hospital across all infants during the study period $(63 \%)$ and nationally (Ryan. 1997), although these rates are not directly comparable as the rate for fullterm infants represents feeding status at day of life $2+4$ (i.e., at discharge), rather than at an average day of life 30 for preterm infants (sample mean length of hospitalization). These findings from a rural catchment area are, consistent with those of other researchers who also found a lower rate of breast milk feeding in porterm infants internationally (Xip, et al 1996) and in low birth weight infants in the US (Ryan, 
1997). Interestingly, the magnitude of the difference between the percentage of breast milk fod pretem and fullterm infants was similar in this study and those conducted internationally, even though the basc rates of breast feeding healthy infants differ significantly across countrics. The consistency of these findings across nations bighlights the important differences between preterm and fullterm infants that affect feeding practices.

Similar to results from studies of unselected healthy infants (Grossman et al., 1990; Kuan ct al., 1999; Ryan et al., 1990), maternal demographic and pregnancy varisbles were related strongly to breast milk fceding in pretcrm infants, including older maternal age, nonsmoking status, and private insurance status, a proxy for socioeconomic status. Furthermore, even among women who fed their pretcrm infants breast milk, older agc was related to more consistent breast milk leeding during hospitalization. These women may bettcr recognize the advantages of breast milk and may have more rcsources at their disposal that make it easier to express milk or to make milk available to the infant more consistently. Other studies with low birth weight infants have found that employment status (Hill \& Aldag, 1996) and cducation (Boo \& Goh, 1999) werc related to breast milk feeding odds. These variables wcrc not available in most pretertm hospital charts, and there[ore, were not included here. However, demographic variables typically are intcr-corrclated. The blocked statistical entry strategy capitalized on thesc intcr-relations among maternal predictors to understand the contribution as a whole; however, the influence of any singlc predictor was attenuated as the odds ratio is adjusted for all other variables in the model.

Relative to preterm inlants delivered in urban, tertiary care medical centers, similar matcrnal demographic corrclates of breast milk feeding were observed in those infants from a non-metropolitan catchmętnt area, namely. maternal agc (Furman ct al., 1998) and insurance status (Furman et al, 2002). Interestingly, smoking status differed between mothers of breast milk and formula led infants, but did not in infants delivered in urban centers. Smoking during pregnancy is more prevalent in Caucasian women, those who are disadvantaged economically, and those who are younger at delivery (Vega, Kolody, Hwang, \& Noble, 1993). Smoking status may be a more important factor in breast feeding in the rural setting. However, its role was not unique, as it was not an indcpendent predictor when considered in the model with other maternal demographic factors.

Unlike results from studies with healthy infants (DaVanzo et al., 1990; Kuan et al., 1999), infant medical condition during hospitalization clearly plays a role in feeding practiccs, cven beyond that of matcrnal characteristics. In preterm infants, therc is sufficient variability in medical condition to examine effects on feeding practices. Infants who were more biologically at-risk, defined by a 5-min Apgar score of $\leqslant 6$, were less likely to be breast milk fed during hospitalization. These findings differ from those of Furman et al. (2002), who found that earlier gestational age and lower weight at birth was related to an increased likelihood of breast fccding. Furman et al.'s study, however, focused on very low and extremely low birth weight preterm infants, and therefore, excluded those with weights above $1500 \mathrm{~g}$, thereby attenuating the differential influence of low Apgar scores on breast milk fceding.

Medical staff may vicw infants with low Apgar scores as more compromised or stressed and not as neurologically cquipped to directly breast feed eventually, and therefore recommend carly formula feeding to avoid future difficulties. Alternatively, parcnts may overestimate the fragilc nature of their preterm infant, which may interfere with lactation duc to maternal anxiety or predispose parents to choose the morc casily measurable formula fccding. Unfortunately, because so few breast milk fed infants were at risk $(n=4)$, it was not possible to determine whether biologic risk, as quantified by low 5-min Apgar scores, differentially impacts breast milk feeding initiation or premature termination during hospitalization. Further studies that include maternal and medical staff perccptions of risk, in addition to biologic risk measures, would be useful to investigate these alternatives.

Interestingly, days of hospitalization and days of oxygen did not differ between breast milk and formula fed groups and did not contribute to breast feeding odds, indicating that duration of treatment and hospitalization did not contribute uniquely to breast feeding likclihood. Among breast milk fed preterm infants, therc also were no diffcrcnces in these infant variables between those who received breast milk more consistently during hospitalization and those who did not. In contrast, these variables were related to the timing of breast milk fceding during hospitalization. Preterm infants who were fed breast milk within 2 days of hospital discharge spent fewcr days on oxygen, were of older gestational age and greater birth wcight, and were hospitalized for a shorter duration, consistent with findings by Furman et al. (1998). Taken together, thesc findings suggest that mothers of carlier bom preterm infants who requirc more intensive neonatal care either are not encouraged or assisted in persisting in breast feeding, or have more trouble sustaining breast milk use during the prolonged hospitalization. Mothers of sicker preterm infants naturally have more health concerns than mothers of healthicr preterm infants, and anxiety affects milk supply (Nisscn, Gustavsson, Widstrom, \& Uvnas-Moberg, 1998). All of these factors may lead to less inclination to continue to use breast milk or carly, unplanned termination of breast milk feeding in sicker preterm infants. 
Unfortunately, it is precisely these infants who may benefit more from the immunuologic properties of breast milk. The carly perinatal period may be a particularly important time for the lactation consultant, NICU nursing staff, and neonatalogists to intervene to promote breast fceding in these families. In comparison to fullterm infants, medical staff play a more prominent role in feeding decisions for preterm inlants due to expertisc in the medical condition and caretaking of the infant. While there are many barriers to successfully breast milk feeding preterm inlants, many women can initiatc fecding with sufficient cducation, hands-on skill teaching, and ongoing support, although they may not appear as capable in the stressful NICU environment. Programs that provide such comprehensive assistance are not available routinely (e.g., Meier et al., 1993); therefore, ongoing verbal communication between medical staff and patients is important.

Identification of the variables that affect breast feecting in spccial populations can bc used to develop and implement unique interventions that serve to modestly increase breast feeding rates as a wholc. Bccause nearly $10 \%$ of all deliveries are preterm, interventions to increase breast feeding in this population have the potential to make important strides towards mecting public health goals. Especially in the context of limited public health dollars, targeted breast fccding intervention campaigns can be successful and cost effective (Wright, Naylor, Wester, Bauer, \& Sutcliffe, 1997). For example, younger women who smoke during pregnancy could be targeted prenatally to promote breast feeding. Interestingly, breast leceding also has been related to delayed post-natal resumption of smoking (O'Campo, Faden, Brown, \& Giclen, 1992). Therefore, pre- and post-natal interventions to increase breast feeding intention and behavior in smoking mothers could positively impact both maternal and infant health. Breast feeding interventions designed for healthy infants necd to be tailored specifically to the nceds of families with preterm infants and must address the specific barriers that these families face, including infant medical complications, the need to express milk and travel to the hospital for feeding, coordination with hospital policies and procedures, and the lack of reinforcement from infant contact that usually occurs during nursing.

The present study has several limitations. First, as is typical of most regional NICUs in non-metropolitan arcas, infants are not served with the most severe illnesses that routinely occur in extremely low birth weight infants who require surgery. Given the relation betwen low 5-min Apgar scores and breast feeding. these infants would be less likely to be breast fed. Mothers of extremely low birth weight infants also are of greater social risk. Inclusion of these women would depress breast milk feeding rates and increase the relation between the maternal and infant variables and breast fecding. In addition, an inclusive criterion for breast milk fccding was employed in the present study because of the special barriers that mothers of preterm infants face when choosing to feed breast milk in the NICU. The definition of "breast fed" varies across studies and a more stringent criterion may have affected rcsults. Despitc thesc caveats, about half of all preterm infants were fed breast milk during hospitalization. Similar to healthy, largcly fullterm infants, breast milk feeding was related to maternal factors in these preterm infants from a non-metropolitan catchment area. Howcver, inlant medical condition was a unique determinant of breast milk fecding in prcterm infants. Subgroups of families can be targeted for intervention to modestly increasc population breast milk feeding rates.

\section{Acknowledgements}

This research was supported in part by a grant from the Central Research Committee, Southern Illinois University School of Medicine to the first author. We would likc to thank Rudolph Foy, M.D., Mcdical Director, the Nconatal Intensive Care Unit staff, and the Medical Records staff at Memorial Hospital of Carbondale for their assistance in conducting this study. The assistance of Jesse Brennan, M.A, and Sylvia Jones, M.A. in data collection also is recognized. The comments from three anonymous reviewer are appreciated. Portions of this paper were presented at the meting of the International Conference for Infant Studics, July 14-17, 2000.

\section{References}

Alexy, B., Nichols, B., Heverly, M. A., \& Garzon, L. (1997) Prenatal factors and birth outcomcs in the public health service: A rural/urban comparison. Research in Nursing and Health, 20(1), 6I-70.

American Academy of Pediatrics Wotk Groun on Breastfecting. (1997). Breastfecding and the use of human milk. Pediatrics, 100(6), 1035-1039.

Boo, N. Y., \& Goh, E. S. (1999). Predictors of breastliceding in very low birthweight infants at the time of discharge from hospital. Journal of Tropical Pediatrics, 45(4), 195-201.

Chomitz, V.R., Cheung. L.W.. \& Liebermun, E. (1995). The role of lifestyle in preventing low birth weight. Future of Children, 5(1), 121-138. Available online at http://www,fu tureofchildren.org/information2826/information_show. htm?doc.id $=79889$.

Cushing. A. H., Samet, J. M., Lambert, W. E., Skipper, B. J., Hunt, W. C., Young. S. 'A., \& McLaren, L. C. (1998). Breastfeeding reduces 'risk of respiratory illness in infants. American Journal of Epldemiology, $J 47(9), 863-870$. 
DaVanzo, J., Starbird, E., \& Leibowitz, A. (1990). Do women's breastfeeding experiences with their first-boms, affect whether they breastfeed their subsequent children? Social Biology, 37(3-4), 223-232.

Department of Health and Human Services (2000). Heulthy People 2010. (2nd ad.) Vol. 1-2. Washington, DC: US Government Printing Ofhice.

Freudenberg, N., Eng, E., Flay, B., Parcel, G., Rogers, T., \& Wallerstein, N. (1995). Strengthening individual and community capacity to prevent discase and promote health: In scirch of relevant theorics and principles. Healh Education Querterly, 22(3), 290-306.

Furman, L., Minich, N. M., \& Hack, M. (1998). Breastfecding of very low birth weight infants. Journal of Human Laciation, $14(1), 29-34$,

Furman, L... Minich, N., \& Hack、 M. (2002). Correlates of lactation in mothers of very low birth wcight infants. Fediatrics, $J(19(4)$, e57.

Grossmatn, L. K.. Fitzsimmons, S. M., Larsçn-Alexander, J. B., Sachs, L., \& Harter, C. (1990), The infant feeding decision in low and upper income women, Cliniral Pediatrics, 29(1). $30-37$.

Hack, M., Taylor, H. G., Klęin, N., Eiben, R., Schatschncidęr, C.. \& Mercuri-Minich, N. (1994). School-age outeomes in children with birth weights under $750 \mathrm{~g}$. New England Journal of Medicine, 331(12), 753-759.

Hill, P. D., \& Aluag, J. C. (1996). Smoking and breastereding status. Research in Nursing and Health, 19(2), 125-132.

Hobel, C. Hyvarinen, M., Okada, D., \& Oh, W. (1973). Prenatal and intrapartum high-risk screening: I. Prediction of the high-risk neconate. American Journat of Obstetrics and Gynecology, 117(1), 1-9.

Kenncdy, K. I., \& Visness, C. M. (1997). A comparison of two US surveys of infant fecding. Joumal of IJuman Lactation. 13(1), 39-43.

Kuan, L. W., Britto, M., Decolongon. J., Schoettker, P. J., Atherton, H. D., \& Kotagal, U. R. (1999). Health system factors contributing to bressifeeding success. Pediatrics, 104(3), e28.

Lefebvre, F., \& Ducharme, M, (1989). Incidence and duration of lactation and lactational performance among mothers of low-birth-wcight and term infants. Cunadian Medical Association Journal, 140(10), 1159-1164.

Lindberg. L. D. (1996). Women`s decisions ubout breastfeeding and matcrnal employment. Journal of Marriuge and the Family, 58(1), 239-251.

liıman, H., Medondorp, S. V., \& Goldfarb, J. (1994). The decision to breast feed: "The importance of fathers' approval. Clinical Pediatries, 33(4), 214-219.
Lizancion, J. L., Maehr, J. C., Wingard, D. L., Felice, M, E. (1992) Psychosocial and economic factors associated with infag foeding intentions of adolesent mothers. Sournal of Adoscen Health, I3(8), 676,681 .

Meier, P. P, Engstrom, J. L., Mangurten, H. H., Estrada, E., Zimmerman, B., \& Kopparthi, R. (1993). Breastfeeding support services in the Neonatal Intensive Care Unit. Journal of Obstetric Gyneculogic and Neonatal Nursing. 22(4). 338-347.

Miller, M. K., Clärke, L. L., Albrecht, S. L., \& Fürmer, F. L. (1996). The interactive effects of race and ethnicity and mother's residence on the adcquacy of prenatal care. Journal of Rural Health, 12(1), 6-18.

Nissen, E., Gustavsson, P., Widstrom, A. M., \& UvnasMoberg, K. (1998), Oxylocin, prolactin, milk production and their relationship with personality traits in women after vaginal delivery or Cesarean section. Journal of Psychosomatic Obstetrics and Gynuecology, $19(1), 49-58$.

O'Campo, P., Faden, R. R., Brown, H. \& Gielen, A. C. (1992). The impact of pregrancy on women's prenatal and posipartum smoking behavior. American Journal of Pre* ventive Médicine, 8(1). 8-13.

Paradise, J. L.4 \& Rockette, H. E. (1997). Otitis media in 2253 Pittsburgh-area infants: Prevalence and risk factors during the first two years of life. Pediatrics, 99(3), 318-333.

Ryan, A. S. (1997). The resurgence of breastfeeding in the United States, Pediatrics, 99(4), el2.

Ryan, A. S., Wysong, J. L., Martinez, G. A., \& Simon, S. D. (1990). Duration of breast-fccding patterns established in the hospital. Clinical Pediatrics, 29(2), 99-107.

Starbird, E. H. (1991). Comparison of influences on breastfecding initiation of firstborn children, 1960-69 vs. 1970-79. Social Science and Medicine, 33(5), 627-634.

US Census Bureau. (2000). State and County QuickFacts. Retrieved July 12, 2002 from http://quickfacts.census.gov/ gfd/states/17/17181.html.

Wright, A. L., Báuer, M., Naylor, A., Sutcliffe, E., \& Clark, L. (1998). Increasing brcastfceding rates to reduce infant illncss at the community level. Pediatrics, $101(5), 837-844$.

Wright, A. L., Naylor, A., Wester, R., Bauer, M.. \& Sutcliffe, E. (1997). Using cultural knowledge in health promotion: Breastreeding among the Navajo. Meallh Education and Behavior, 24(5), 625-639.

Yip, E., Lee, J., \& Sheehy, Y. (1996). Breast-feeding in a neonatal intensive care unit. Journal of Paediatrics und Child Healh, 32(4), 296-298.

Yu, V. Y. H., Jamicson, J, \& Bujuk, B. (1981). Breast milk feeding in very low birthweight infants. Australian Paediatric Journal, $17(3)$, 186-190. 